\title{
Scanning Electron Microscope
}

National Cancer Institute

\section{Source}

National Cancer Institute. Scanning Electron Microscope. NCI Thesaurus. Code C78814.

An electron microscope that scans the surface of a sample with a beam of electrons and detects the interaction of the electrons with the atoms on the surface to produce a topographical image of the sample. 